\title{
Developing a New Profession: A Case Study
}

\author{
Denise Hevey \\ The University of Northampton, United Kingdom
}

\begin{abstract}
Professions have traditionally been the province of male-dominated, educated elites who self-regulate through codes of conduct to maintain public confidence and in return can expect high status and remuneration for their services. The purpose of this paper is to explore the meaning and challenges of professionalization in a sector which runs counter to this stereotype. The early years sector in the UK is characterised by low qualifications, low pay, gendered perceptions of work roles and small, dispersed and highly variable settings. Early Years Professional Status (EYPS) was introduced in 2007 as part of government strategy along with other workforce reforms aimed at improving the quality of provision for young children. The nationally designed 'validation' (assessment) process is explained and a 'capacity building' approach to implementation within one English region is presented. Alternative models of professionalism are discussed and the emergent roles and identities of EYPs are explored based on focus group evidence collected three years into the roll out of the training programme. The importance of Continuing Professional Development is discussed as a means of consolidating professional identity and preventing professional isolation. However, questions are raised about the long term sustainability of the profession unless fundamental issues of pay and conditions are addressed to make it commensurate with other graduate-level professions.
\end{abstract}

\section{Introduction}

The ancient professions such as the law and religious ministry, evolved in close relationship with the early development of universities and rapidly became the provinces of the elite. By the C19th other professions, such as medicine and engineering, were developing to fill particular functions in society. Overtime they imposed qualification requirements and codes of conduct for the protection of the public and, some would say, to restrict access in or order to maintain fee levels. In the UK, chartered professions, such as accountancy and psychology, are largely selfregulating and can restrict rights to practice under particular titles. Most professional bodies operate registration and disciplinary functions, some with associated statutory councils, (such as the General Teaching Council or the General Medical Council) and serious misconduct can lead to being denied membership or being 'struck off'. Increasingly, professions in the UK are moving to adopt compulsory Continuing Professional Development (CPD) requirements through which members must show that they are keeping themselves up-to-date with developments in their specialist field.

Despite the ease with which we can identify professions, defining the characteristics of a profession or of professionalism is not easy. As Oberhuemer [1] has argued:

'Professionalism is a situated concept, embedded like our understanding of children and childhood within specific historical, socio-cultural, organisational, economic and political contexts'

For education and social care professions, reflective practice - the process through which one reflects on the strengths and weaknesses of ones own and others practice in order to bring about improvement - has become accepted as essential at all levels. One might describe this as a key feature of professionalism regardless of the context or curriculum adhered to or the nature of the client group. On the other hand according to Westcott [2] a profession is a community of practice that exhibits command of a specialist body of knowledge, sets standards for practitioners and regulates its own standards of practice. It is clear, therefore, that individuals can have characteristics of professionalism without membership of, or identity as, a profession.

Professionalization of a sector - the process through which leading workforce members achieve professional status and others roles and qualifications are defined in relation to them - is something that normally evolves over an extended period of time. For example, a fully fledged graduate profession has taken teaching more than 50 years to achieve in the UK progressing from largely unqualified teachers pre-war, through Certificate of Education and Diploma requirements and finally to a graduate only training programme in the 1970-80s. Similar changes have taken place in Nursing for whom graduate level requirements are even more recent. A corollary of 
professionalization has often been the identification of para-professional roles, some of which have become recognised vocations/ professions in their own right, for example, para-medics in emergency services or legal executives who deal with property conveyancing.

\subsection{The early years policy context}

Until the late 1990s the UK was characterised by low investment in early years' services, low qualifications amongst childcare staff and poor pay and conditions other than for teachers in the relatively small proportion of nursery classes attached to maintained schools [3]. The incoming Labour government of 1997 put expanding childcare at the heart of its agenda, largely as part of an anti-poverty strategy that saw female employment as a way of reducing child poverty for low-wage families and single parents. At this time Sure Start was set up as a network of local programmes providing a range of services for children under five and their families in the most disadvantaged areas of England. This had some similarities to the American Head Start compensatory education programme but there were also important differences. For example, Sure Start local programmes had a particular focus on under threes and their families. They were encouraged to seek the views of the local community and respond to local need, and, in order to avoid stigmatisation, the services that they offered were to be universally accessible within the neighbourhood rather than targeted exclusively at those most in need [4].

In 2001 Ofsted (Office for Standards in Education) took over the regulation and inspection of early years services in England from 150 different local authorities and for the first time imposed qualification requirements for those in charge of settings alongside national minimum standards for daycare [5]. However, the requirement was set at a level 3 National Vocational Qualification (broadly secondary school exit level).

In 2003 the first important findings from a major longitudinal study of the Effectiveness of Pre-School Provision (EPPE) were published [6]. These showed clearly for the first time in a UK context that the quality of outcomes for children was closely related to the quality of early educational experiences provided. Moreover, that the effects were more extreme on children from disadvantaged backgrounds such that, without high quality input, children starting off with broadly the same educational potential quickly diverged according to social class. Not surprisingly perhaps, EPPE also found that the quality of early years' provision in turn was highly dependent on the qualifications of staff, in particular whether or not the leader of the setting held a graduate level qualification - normally meaning qualified teacher status.

In 2004 a national childcare strategy was launched which included a commitment to free nursery education places for all three and four year olds and a range of incentives for increasing early education and childcare (ECEC) availability through the Private, Voluntary and Independent (PVI) sector [7]. The target was for one million additional daycare places to be created but the government came under criticism, backed by the EPPE evidence, for a strategy that seemed to be 'never mind the quality - feel the width'. Increasingly the need for workforce reform could not be ignored

The Children Act of 2004 established the Children's Workforce Development Council (CWDC) and charged them with developing a workforce strategy to up-skill the whole of the children's workforce. The initial consultations around the development of a workforce strategy, heavily influenced by the EPPE findings, first mooted the idea of universal graduate leadership for early years' services [8]. Unlike New Zealand where a 'new teacher' model had been implemented, the UK looked to the European tradition of social pedagogues for inspiration [9]. By 2006 the Children's Workforce Strategy [10] confirmed that government had opted for a new form of multi-disciplinary graduate professional for the PVI sector in England, to be trained in all aspects of health, care and educational development and capable of working across the birth to five age range. This contrasted sharply with early years teachers whose training in the UK is across the 3 to 8 age range and whose primary focus is mainly on educational achievement [11]. Early Years Professionals were to have a status broadly equivalent to teachers, but at least initially, without the nationally recognised pay, terms and conditions and career structures of the teaching profession [12]. The government argued at the time that such requirements would have been impossible to impose on the fragmented PVI sector that accounted for a substantial part of services for under fives.

\subsection{The design of Early Years Professional Status (EYPS)}

Early Years Professional Status was to be awarded by the CWDC after validation following a tightly prescribed process in relation to 39 national standards. At the same time the curriculum frameworks for young children were undergoing major reform. The Childcare Act 2006 effectively abolished the distinction between care and education for young children and paved the way for the introduction of a new Early Years Foundation Stage curriculum [13] for the birth to five age range by September 2008 which applied to all care 
and education settings including nursery and reception classes in schools. While maintained schools retained a requirement for qualified teachers in all classes, the government set a target of an EYP in every setting providing ECEC full time in the PVI sector by 2015. The main purpose of the EYP was to be a 'change agent' driving practice improvement and able to:

'... lead practice in the Early Years Foundation Stage (EYFS), support and mentor other practitioners and model the skills and behaviours that safeguard and promote good outcomes for children' [14].

The University of Northampton was one of 11 education and training providers selected to pilot the validation process for the new award in Autumn 2006 and became an 'Approved Provider' delivering four different pathways to achieving EYP status from January 2007 (a fifth undergraduate pathway has since been added). The University had already decided to work with and through Local Authorities, seven of whom from across the East Midlands of England were represented on its Steering Group. The model adopted was one of 'capacity building' through which some local authority advisory staff, who visit and advise PVI settings in the course of their work, were trained to be EYPS assessors in the first wave. Later, practitioners who had achieved EYP status themselves were encouraged to become assessors and mentors for the subsequent cohorts.

The EYPS pathways were designed to meet the needs of different practitioners depending on previous qualifications and experience:

The Validation Pathway (4 months) was designed for graduates with a relevant degree and recent experience, including at a supervisory or leadership level, across the birth to five age range. In such cases, no additional education or training was deemed necessary and the early years' practitioner moved straight to four days of preparation for the different elements of assessment. These included an initial half day 'Gateway' assessment of communication, leadership and decision-making skills modelled on a management assessment centre; followed by submission of seven prescribed tasks demonstrating knowledge and competence across the 0 -5 age range; finally a full-day setting visit during which evidence could be directly observed and witnesses interviewed. All EYPS pathways culminated in this same validation process and the candidate files and assessor judgements were subject to a rigorous national system of external moderation.

The Short pathway (6 months part-time) was designed for graduates with a relevant degree but some gaps in their training or experience. Typically nursery and primary qualified teachers whose training did not encompass care and education of children under three.

The Long pathway (15 months part time) was primarily designed for those with a vocationally related
Foundation Degree in Early Years (240 credits or HE Diploma level) who need to ‘top-up’ with a minimum of a further 60 credits for an Ordinary Degree or 120 credits for an Honours degree before being eligible to undergo EYPS validation.

The Full time training pathway (12 months ) was similar in structure to a post-graduate teacher training course comprising 18 weeks of intensive education/ training and 18 weeks of placements and is designed for new graduates with relatively little relevant knowledge or experience and for career changers.

The fifth pathway (18 months) was introduced, following a brief pilot phase, in October 2009 in order to provide a professional practice route through the second and third year of the BA Hons Early Childhood Studies degree. This led immediately after graduation to a final extended professional development stage based on placements or work experience.

The provision of such a wide variety of pathways to achieving the status recognised the variation in qualifications and experience within the workforce at the starting point of professionalization. It was not anticipated that all of these routes would be needed in the longer term.

\subsection{The challenges of implementing EYPS}

When EYPS was first introduced in 2007 around $61 \%$ of those working in group daycare were qualified to level 3 (secondary education) or higher and only $3 \%$ were graduates) [15]. The workforce of $350-500,000$ was $98 \%$ female and in day care, around $30 \%$ of the staff were under 25 contributing to high turnover. The government target of achieving graduate leadership of all 15,000 daycare settings by 2015 was hence extremely ambitious. The challenge was not just individual professional development on a mass scale, but one of professionalization of the workforce as a whole in terms of raising the aspirations of all existing and potential leaders to degree level. On top of this, was the creation of a new form of multi-disciplinary professional role and identity that cut across existing professional/ discipline boundaries of health, education and social care.

The early years' sector has been bedevilled by the glorification of 'mothering' leading to assumptions that caring for young children requires no more than female genes and a kind heart. Professionalization of the workforce therefore required the promotion of education, training and a professional reflective approach across all job roles and levels within the sector - using an inclusive rather than exclusive definition of professionalism [16].

EYPS does not, as yet meet the minimum requirements for a profession set out by Westcott [2]. It does not 'own' a specialist body of knowledge because 
it draws on knowledge from a range of disciplines and professional areas with boundaries as yet not clearly defined. EYPS has national standards, but these are not self-defined but set down externally by government agency. It lacks a framework for self-regulation, however, the fact that it was created as a status (which can be removed) rather than a qualification (which cannot) signals the intention to move towards professional registration in the long term.

EYPS as a new profession has been artificially imposed by central government rather than organically grown. The early years' sector was being asked to undergo transformation from largely unqualified to graduate level leadership in less than 10 years - a process that has taken other professions more than 50 years to achieve. More significantly, the institutions involved were not state maintained and standardised but small scale, dispersed and highly varied PVI settings (from community-run play groups in church halls to private day nurseries with new purpose built buildings or formal nursery units attached to independent schools) over which the government had little control. In order to 'incentivise' the PVI sector towards professionalization the government initially invested £250 million over three years in a Transformation Fund (later known as the Graduate Leader Fund) to be administered by Local Authorities. This 'carrot' would provide up to $£ 5,000$ per annum for settings to recruit a graduate, to grow their own staff into graduates, to retain graduates through pay enhancement and to support the training and development of other staff in the setting. Nevertheless, it can still be argued that the government was trying to professionalize the workforce on the cheap because, unlike New Zealand, it shied away from making EYPs truly equivalent to teachers by establishing them on professional terms and conditions of employment because of the cost implications. In addition, in order to meet its agenda for the affordability of childcare, the government capped the fees of all settings in receipt of funding for free nursery education places for three and four year olds. This would make it difficult for the majority of settings to recoup graduate-level wages from fee increases even in the more prosperous areas. On the other hand, in poor areas demand-side subsidy in the form of the childcare element of Working Tax Credit was poorly understood and had low take-up, again restricting the potential of PVI settings to cover the costs of a graduate level wage. These factors, together with the current financial climate of cuts in all bar the most essential services, threatens the long-term sustainability of employing graduates in PVI daycare settings.

Of course, up the other sleeve the government held a 'stick' in the form of regulatory requirements that could be enforced through Ofsted. Post 2015 it was widely expected that the qualification requirements for registration of daycare settings would be changed to include at least one graduate EYP on the staff and that the bar would be raised for others such that a level 3 qualification would become the norm [17]. However, as a result of the recent election in the UK, the new coalition government has all services and strategies under review. The new mantra is reducing bureaucracy/ regulation and devolving decisionmaking and accountability to local levels coupled with targeting services more closely at the disadvantaged. Within this context, universal early years services have been largely protected and the previous government's commitment to extending the hours of free 'education' for three and four year olds (from 12.5 to 15 hours per week) has been honoured. There is, however, considerable uncertainty about the future of workforce training and the coalition government has announced its intention to develop a new Workforce Strategy by March 2011.

As with many government initiatives, EYPS status was rapidly rolled out on a national scale prior to full evaluation of the delivery systems. An initial evaluation of the pilot phase at the University of Northampton identified a number of issues that could be potential barriers to successful implementation [18]. Firstly the assessment system was overly bureaucratic and reliant on paperwork rather than observation of practice. This threatened to undermine the credibility of the process in the eyes of other professionals. Secondly, the level of the demand of the National Standards was pitched beyond effective graduate-level personal practice and required demonstration of leadership and support of others. This was not comparable to other professions, such as teaching, in which a newly qualified teacher (NQT) would be subject to ongoing supervision and support for a further year after qualifying. Thirdly, and perhaps most significantly, there was no parallel system for recognition of the skills and experience of the most long-serving and expert members of the workforce who lacked formal qualifications. This risked creating a level of antagonism and resentment around professionalization of the workforce that could potentially undermine the whole strategy. The University's experience was that resentment sometime spilled over into treatment of aspiring graduates and EYP students on placement in settings with highly experienced but unqualified managers. This danger was well illustrated by a quote from a focus group of students which is the subject of discussion later in this paper.

"In most of the private day nurseries it's so difficult to bring about...change because most of them I swear don't want it... it's like you were coming in to disrupt the other team." Student

Whilst not compromising the rigour of EYPS requirements, the CWDC might have considered 
adoption of a 'grandmother principle' through which exceptionally, the most experienced and senior practitioners might have gained EYPS status (in the absence of an academic degree) through a system of Accreditation of Prior Experiential Learning based on a portfolio of evidence of achievement. It is not unusual during the creation of a new profession for such systems to be put in place for a short period and then phased out as full education and training requirements become widely established (for example, the Engineering Institutes and Higher Education Academy in the UK).

In the event these suggestions were ignored and initial take up of EYPS was disappointing. However, the introduction of EYPS stimulated demand for workbased education and training at undergraduate level and support from the Graduate Leader Fund to cover fees enabled unprecedented numbers of early years practitioners to embark on higher education for the first time. By 2010 these students were starting to come through onto EYPS training in large numbers. According to the CWDC, nationally some 5,800 practitioners have now gained EYP status and a further 3,100 were enrolled on qualifying programmes in the academic year 2010-11.

\section{EYP roles and identity}

The EYPS initiative is now on course for achieving the initial target of 20,000 EYPs by 2015. However, there are still a number of questions and concerns surrounding the creation of this new profession. First and foremost of which is what difference does the status make? This question can be considered on a number of levels. At one level, a large scale impact evaluation, funded by the CWDC, is being carried out across England by Wolverhampton University and is due to report at the end of 2010. On another level, it is possible to ask on a small scale whether or not having EYP status has made any difference to the lives of experienced practitioners and whether a distinctive EYP role and identity can be identified or is emerging.

This latter was the subject of a small scale qualitative study based on five hour-long focus groups involving (a) experienced practitioners who had qualified as EYPs in the first wave, (b) students at the end of the Full-time training pathway who were about to become EYPs and (c) workforce development officers (stakeholders) from Local Authorities whose job it is to ensure sufficient EYPs for every daycare setting in line with government policy. A standard set of questions were posed to structure the discussion:-

1. What do you see as the core role of an EYP?

2. How does the EYP role differ from that of other EY practitioners?
3. How does the EYP role differ from that of other professionals?

4. What does being an EYP mean to you personally?

5. Any other issues that you want to discuss?

The focus group discussions were carried out in June - July 2009. Recordings were transcribed and a simple thematic approach taken to analysis.

\subsection{Differentiating the role of EYP}

The first main finding was that, although trainees, practitioners and stakeholders could all articulate the role expectations set down by the CWDC, a distinct role of EYP did not as yet exist.

'I don't think in the work place there is an EYP role ...well it's not advertised...it's always nursery nurse, head of room like'. Student

'I don't think it's that distinct yet, is it? ... because even within our network, we've all got such different roles ...if we're managing a setting, there's other people who are managing settings who are not EYPs and, if it's your own business - there's lots of business people who are not even Early Years people running this.' Practitioner

'I mean in lots of ways the role's still emerging, isn't it? You know, it's evolving.' Practitioner

Students particularly found this lack of a distinct role and identity frustrating.

'With teachers when they are training they are not classed as students, they are classed as trainee teachers, yeah... just the terminology is completely different...we are not trainee professionals, we are students.' Student

'...isn't that because everyone knows what a teacher is trying to do... whereas people go "what is an EYP?".' Student

'Like you say, there's not many people at the moment that even know what an EYP is.' Student

There are a number of reasons why the EYP role was not seen to be distinct and identifiable at this early stage in its evolution. Firstly, in the UK with a commitment to marketization within a mixed economy of care there are huge variations between ECEC settings in terms of their scale and nature - from small, community run pre-schools in rural areas, to company run chains of nurseries in affluent suburbs and large, multi-agency Children's Centres in inner cities. This in turn is linked to variations in the role of graduates with EYP status. Some may be room/ age group leaders in large nurseries, others are nursery-wide curriculum leaders, others still are owner/ managers or LA advisory staff. Secondly, a major issue at the time was the lack of awareness of EYPS as a national initiative amongst parents and the general public and also amongst the general staff in settings. This was 
largely because the government, through the CWDC, decided not to widely publicise the introduction of EYPS for fear that this would raise unrealistic expectations of graduate leadership before sufficient trained and qualified staff were available. Finally, the experienced practitioners completing EYPS at this early stage were mainly pilot groups -'early adopters'who were already graduates and leaders in ECEC settings. This meant their core roles were not likely to change with the newly achieved status. One might, therefore, expect that clearer differentiation of the role of an EYP to emerge as a larger proportion of the current workforce (holding level 3 qualifications) come through to graduate with early childhood degrees and to undergo level 6 training for EYPS.

With regard to direct comparisons with the role of teacher or other professional it is not surprising, given the previous discussion, that practitioners and students also found this difficult to articulate.

'At the moment I don't think it does because I don't think there is an EYP role.' Student

'I've been in settings that have got an EYP ...I wouldn't say I could see a difference. She just seemed to be working as a room leader just like anybody else. I don't think there's any difference even though she's got the status." Student

However, there were interesting comments from the practitioners, some of whom had trained and practiced as teachers in maintained schools prior to working in a PVI setting, who found that the EYP role gave them more freedom and autonomy to respond to children's interests.

'All this observation on all these children, yet we've got $a$ head (teacher) saying...sort of almost discounting it... concentrating on targets and not understanding coming into the (reception) classroom and you having changed what you're doing because a child has seen a ladybird... they've got targets to meet and forms to fill in and the frustration. I think that is why I thought "Oh no, I'm not going back in that" ... In actual fact we have got a lot of freedom, so yes, we're constrained by the EYFS (i.e. the curriculum framework for the Early Years Foundation Stage), but I don't really feel it's a constraint anyway, I feel it's a freedom because I think it is how you want it to be.' Practitioner

'I think in (EY) settings (compared with schools) they do have a better understanding of actually the relationship - that partnership (with parents) compared to how crucial it is actually in the child's development.' Practitioner

The stakeholder group were also aware of the comparisons and saw the EYPs as offering something different while raising the status of working with the youngest children.

'I think the strength of them (EYPs) is being totally early years embedded. In the schools there is that missing - the strong knowledge and understanding of early years.' Stakeholder

'They haven't come at it from career progression... they did not see themselves as equal (to teachers) before but now they are beginning to realize that they are.' Stakeholder

'I don't think they see it as just a 'job'. They are totally committed - they care.' Stakeholder

\subsection{Different models of professionalism}

The second main finding was that students and experienced practitoners appeared to be operating according to different models of professionalism. Students appeared to adhere to what might be described as a managerial/technical model that prescribes standards and outcomes and sees EYPs, or indeed teachers to whom Moss would argue this also applies within current government policy, as '...technicians trained in right answers, not professionals trained to reflect and question.' [19]. This can be illustrated by the following quotes from the full-time student group:

'Somebody who leads and supports all of them and tries to change, I mean practice, by being a good role model, and observing to see if there are areas you can change really.' Student

' After reading guidance, because I believe in, you know, in doing things by the book, my role includes, I mean, leading and supporting, changing situations, you know, so that's what I'm going to be doing.' Student

Experienced practitioners, on the other hand, tended towards what Oberhuemer describes as a democratic professionalism model '...based on participatory relationships and alliances between professionals and other stakeholders' [1]. She goes on to argue that, within the democratic model: '.. work with young children could be described as relational, analytic and reflective, cultural and aesthetic, and drawing on a broad, cross-disciplinary knowledge base.'

The discussions of experienced practitioners emphasized personal responsibility for quality and continuous evaluation and improvement but also the importance of inspirational leadership and empowerment of others:

'I think an EYP is someone who is really passionate about their work. Who's got completely, utterly interested in early years and improving the quality of it all the time.' Practitioner1

'I suppose what we're really saying is that an EYP is someone who is always self-evaluating and looking to move forward, aren't they? And being open to new ideas.'Practitioner2 
' To me it's more of an equipping role - to help people emerge as being really excellent in this field... you've got to get them to value themselves first.'P Pactitioner3 'So it's an inspirational role.' Practitioner1

'Yes...To try and allow people to value themselves enough to say 'actually I want to go on that training because I want to better myself', not because I've been told to do so.' Practitioner 3

'... and it's empowering other practitioners to move forward' Practitioner1

The experienced EYPs also demonstrated professional autonomy and a mature democratic professionalism through their confidence to question and challenge practice and directives. This is well illustrated by what they said:

'You need to know what the benefits of change might be ...I think it is important to have the confidence to say "well, I'm not going to have this just because I've been told to have this" ..."I will decide to have this on the basis of..." .' Practitioner

'I've done exactly the same. I've had things thrown at me from the improvement advisers... and I said 'I'm not going to because I believe this is about our ethos, this is what I believe about the children that we have here and we do this for a reason.' Practitioner

In contrast the student/ trainees, perhaps not surprisingly, lacked this self confidence and felt that authority to challenge and change came from appointed positions in the hierarchy.

'It's like if the manager says something you have to do it because she's the manager whether you fully agree with it or not. Whereas if you haven't got that status kind of thing then it's hard ... they can still turn round and say no.' Student

Experienced practitioners were also able to see the wider picture and to recognise the importance of workforce development in the longer term. They were already in employment and were more positive about the future.

' The leader of the setting, you know, I can see why they need to be an EYP because a lot of the quality comes from the top down. It's always the leader who has the impact on what's actually happening in the setting, you know, and if there is a change of leadership you can have a very good quality setting that will suddenly just die.' Practitioner

\subsection{Other issues}

Finally, focus group participants were invited to raise any other issues that they felt were important. Many of the experienced practitioners in this small sample volunteered that they had been sceptical of the value of EYPS and surprised with the impact that the training programme had had on themselves, given that in their case it was only a short course of professional updating across the $0-5$ age range prior to the validation process.

' Before I was reluctant...to progress professionally, I think really because I was in my comfort zone and very happy...It was actually probably the research part of it and the actual writing the assignments...it brought this knowledge and sort of, like you say, consolidated why I'm doing this.' Practitioner

' I think being an EYP for me - although I didn't think it would change what I was because I (already) believed I was a professional - it has updated a lot of my knowledge and practice and understanding... and has allowed me to do that and enabled me to.' Practitioner

In particular, there was striking evidence of the impact on qualified early years and primary teachers whose original training covered the $3-8$ or 5 to 11 age range.

' I think my own perception of the value of children under three, their education, I think that changed. I think I'd got a block there that nothing happens until children are four.' Practitioner

Workforce Development Officers in the stakeholder focus group were fulsome in their praise of what had been achieved already and saw the EYPs as a new breed of highly committed professionals motivated by their concern for children:

' It's the first time I've really met a group of people who're not just thinking about themselves or their setting but about outcomes for children. With other professionals they may be coming at it from a different angle.' Stakeholder

' All of a sudden I've got practitioners helping me partners in what we do... taking responsibility for training across all levels in their setting...(as a result) we're working towards inverse proportionality in terms of support - concentrating more support on those lesser achieving settings.' Stakeholder

\section{Continuing Professional Development}

Unlike teachers, the vast majority of EYPs work in small scale, isolated, PVI settings in which they are the only person qualified to graduate level. Without moral support and intellectual stimulation from outside, newly qualified EYPs would inevitably become isolated and might find it hard to develop professional identity and sustain enthusiasm for continuous improvement. This potential problem was recognised by CWDC when at the end of 2007 they announced funding for Local Authorities to support newly qualified EYPs. In the East Midlands, as well as starting to set up local networks for the initially tiny number of EYPs in each LA area, all seven LAs signed up to a regional support system operated through the University of Northampton. This was to offer 
continuing access to the University's academic library and electronic learning environment; invitations to internal research seminars and termly 'partnership evenings' with invited speakers; bi-annual update/ networking conferences; and flexible accredited CPD/ masters level modules.

What is now evident from the increasing number of EYPs who are active in local networks and who continue to engage with the University through open lectures and conference attendance, is how much they value the chance to meet and to discuss their work with like-minded individuals. In our experience the role of CPD has been vital in supporting the development and consolidation of professional identity for this emergent group. It has helped to extend their critical selfreflection and evaluative capacities so that they can offer reasoned justifications for proposed improvements with confidence. It supports them in informed, autonomous decision-making through independent access to up-to-date theory and research evidence. In other words, through the development of a 'community of practice', CPD supports the change agent role and has the potential to move the fledgling EYPs along a trajectory from 'technical prescription' towards the ideals of the mature, 'democratic professionalism' espoused by Moss [19] and Oberhuemer [1].

Members of the stakeholder focus group also recognized the importance of networking and CPD and were concerned that government commitment would be sustained in the longer term:

'They're doing a brilliant job, they're doing so much...forget about salaries...but if we have to curtail the support...?' Stakeholder

'If we're going to keep them motivated - it's quite new and exciting at the moment - we have to be able to do something to keep them going.' Stakeholder

Much of the evidence for the impact of CPD is anecdotal at this stage. However, hard evidence can also be seen in the growing number of EYPs who are coming forward for training as assessors and mentors for the next generation of EYPS trainees. At the University of Northampton, although the majority of teaching is still done by faculty members, more than $30 \%$ of the 68 trained EYPS assessors and mentors are now 'home-grown' alumni of the EYPS training programme. This enables trainees to be supported in their professional development by committed practitioners who are still actively practicing and hence understanding of day-to-day challenges.

\section{Conclusion}

EYPS was less than four years old when this small scale study was undertaken showing as yet, no clear role and identity and little public recognition associated with the new status. The differences in the models of professionalism adopted by students and experienced practitioners could just be put down to the confidence that comes with experience and with fully internalising the knowledge and values of professional training. However, I have argued that CPD and network support have a critical role to play in accelerating the process of professional identity formation, particularly where there is no ready established professional role and identity to act as a reference point. To reiterate, the issue here is not just about developing an individual professional but rather about the development of a new profession at the same time as professionalizing the wider workforce.

In the absence of a democratic approach to professionalism [19] predicted a future in which:

'All this will mean a workforce increasingly governed by detailed procedures and pre-specified outcome goals, standardised production methods implemented by a workforce of low-level technicians accustomed to measuring themselves and children against external norms.'

The evidence presented here suggests that his view is unduly pessimistic and that this new profession has the potential to develop a strong autonomous, professional identity. They may work within an outcomes culture but they will not be governed by it if they do not see the requirements as relating to improving practice or in the best interests of individual children.

Given the scale and nature of most settings in the PVI sector, membership of a professional 'community of practice' can only be achieved by looking outside the setting and networking with others through CPD opportunities. The long term success of the implementation of EYPS may, therefore, be as dependent on CPD and support networks as it is on solving the wider problems of recognition, sustainability and graduate level salaries.

\section{References}

[1] Oberhuemer, P., (2008), Who is an Early Years Professional? Reflections on Policy Diversity in Europe, chapter 12 in Miller, L. and Cable, C. (2008) Eds. Professionalism in the Early Years, London: Hodder Education.

[2] Westcott 2004 cited in Miller, L.K., (2008), Developing New Professional Roles in the Early Years, Chapter 2 in Miller, L. and Cable, C. (2008) Eds. Professionalism in the Early Years, London: Hodder Education.

[3] OECD (2006), Starting Strong II: Early Childhood Education and Care, Paris: OECD.

[4] NESS (2003), Characteristics of Sure Start Local Programme Areas: Rounds 1 to 4. London: Birkbeck. 
[5] Ofsted (2002), Early Years: Early Days. London: Ofsted HM1642.

[6] Sylva, K., Melhuish, E., Sammons, P., Siraj-Blatchford, I., Taggart,B. and Elliot, K. (2003), The Effective Provision of Pre-School Education Project; Findings from the PreSchool Period. DfES Research Brief No: RBX15-03, London: DfES.

[7] HMT (2004), Choice for parents: the best start for children- a ten year childcare strategy London; The Stationery Office.

[8] DfES (2005), Children's Workforce Strategy: a consultation document. Nottingham; DfES Publications.

[9] Peeters, J. (2008) The Construction of a New Profession: A European Perspective on Professionalism in Early Childhood Education and Care. Amsterdam: SWP Publishers.

[10] DfES (2006), Children's Workforce Strategy; Building a World-Class Workforce for Children, Young People and Families. Nottingham; DfES Publicaitons.

[11] Devereux, J. and Cable, C. (2008), The Early Years Teacher chapter 4 in Miller, L. and Cable, C. (2008) Eds. Professionalism in the Early Years, London: Hodder Education.

[12] Miller, L. (2008), Developing New Professional Roles in the Early Years, Chapter 2 in Miller, L. and Cable, C. (2008) Eds. Professionalism in the Early Years, London: Hodder Education.

[13] DfES (2007), The Early Years Foundation Stage: Setting the Standards for Learning, Development and Care for Children from Birth to Five. Nottingham: DfES Publications.

[14] CWDC (2007) Early Years Professional Status; Prospectus. Leeds; CWDC, Children Act 2004,

www.legislation.hmso.gov.uk/acts/ acts2004/20040031.htm, Childcare Act 2006, www.legislation.hmso.gov.uk/acts/ acts2006/20060021.htm.

[15] Owen, S. and Haynes, G. (2010), Training and workforce issues in early years, chapter 14 in Pugh, G. and Duffy, B. (Eds) Contemporary Issues in Early Years (5 $5^{\text {th }}$ edition) London: Sage.

[16] Paige-Smith, A. and Craft, A. (2008), (eds) Developing Reflective Practice in the Early Years. Maidenhead: Open University Press.
[17] HM Government (2009), Next Steps for Early Learning and Childcare: Building on the 10-year Strategy. Nottingham: DCSF Publications.

[18] Hevey, D., Lumsden, E. and Moxon, S. (2007), Early Years Professional Status: Pilot Evaluation and Issues. Paper presented at Seeds for Change, International conference of the Centre for Early Childhood Development and Education, February 2007, Dublin.

[19] Moss, P. (2008), The Democratic and Reflective professional: Rethinking and Reforming the Early Years Workforce chapter 11 in Miller, L. and Cable, C. (2008) Eds. Professionalism in the Early Years, London: Hodder Education. 